\title{
EIGENVALUES OF DISCRETE STURM-LIOUVILLE PROBLEMS WITH SIGN-CHANGING WEIGHT AND COUPLED BOUNDARY CONDITIONS
}

\author{
Chenghua Gao, Fei Zhang and Maojun Ran
}

\begin{abstract}
In this paper, we study the eigenvalues of discrete Sturm-Liouville problems with signchanging weight and coupled boundary conditions. The exact number (including multiplicity) of the real eigenvalues is obtained. The number of positive eigenvalues is equal to the number of positive elements in the weight function, and the number of negative eigenvalues is equal to the number of negative elements in the weight function. Meanwhile, the interlacing properties of these eigenvalues are also obtained as the parameter varies. These results extend the relevant existing results of discrete left-definite and right-definite Sturm-Liouville problems with coupled boundary conditions.
\end{abstract}

Mathematics subject classification (2010): 39A21, 39A70, 47A75.

Keywords and phrases: Second-order linear difference operator, sign-changing weight, coupled boundary conditions, eigenvalue, interlacing.

\section{REFERENCES}

[1] M. BôcHER, The smallest characteristic numbers in a certain exceptional case, Bull. Amer. Math. Soc., 21 (1914), 6-9.

[2] E. L. INCE, Ordinary Differential Equations, New York (NY): Dover, 1956.

[3] A. ZetTL, Sturm-Liouville theory, Mathematical Surveys and Monographs, 121 (2005).

[4] P. A. Binding AND PATRICK J. BROWNe, Left definite Sturm-Liouville problems with eigenparameter dependent boundary conditions, Differ Integral Equ., 12 (1999), 167-182.

[5] A. Anane, O. Chakrone And M. Moussa, Spectrum of one dimensional p-Laplacian operator with indefinite weight, Electron. J. Qual. Theory Differ. Equ., 17(2002), 11 pp.

[6] Q. Kong, H. Wu AND A. ZetTL, Singular left-definite Sturm-Liouville problems, J. Differential Eqns, 206 (2004), 1-29.

[7] A. Constantin, A general-weighted Sturm-Liouville problem, Ann. Sc. Norm. Super. Pisa, 24(1997), 767-782.

[8] X. HAO, J. SUn AND A. ZETTL, Canonical forms of self-adjoint boundary conditions for differential operators of order four, J. Math. Anal. Appl., 387 (2012), 1176-1187.

[9] Y. YUAN, J. SUN AND A. ZETTL, Eigenvalues of periodic Sturm-Liouville problems, Linear Algebra Appl., 517 (2017), 148-166.

[10] M. Dan, J. Sun, J. AO AND J. XIE, The modified Parseval equality of Sturm-Liouville problems with coupled boundary condition, Oper. Matrices, 12 (2018), 757-771.

[11] M. DAN, J. SUn AND J. Ao, Asymptotic behavior of eigenvalues and eigenfunctions of SturmLiouville problems with coupled boundary conditions and transmission conditions, Oper. Matrices, 9(2015), 877-890.

[12] F.V. ATKInSon, Discrete and Continuous Boundary Problems, Academic Press, New York, 1964.

[13] A. JiRARI, Second-order Sturm-Liouville difference equations and orthogonal polynomials, Mem. Amer. Math. Soc., 542(1995).

[14] W. G. Kelley and A. C. Peterson, Difference Equations and Its Applications, Academic Press, New York, 1991.

[15] R. P. Agarwal, M. Bohner And P. J. Y. Wong, Sturm-Liouville eigenvalue problems on time scales, Appl. Math. Comput., 99 (1999), 153-166.

[16] C. GAO AND R. MA, Eigenvalues of discrete Sturm-Liouville problems with eigenparameter dependent boundary conditions, Linear Algebra Appl., 503 (2016), 100-119. 
[17] Y. SHI AND S. Chen, Spectral theory of second-order vector difference equation, J. Math. Anal. Appl., 36(1998), 179-192.

[18] Y. WANG AND Y. SHI, Eigenvalues of second-order difference equations with periodic and antiperiodic boundary conditions, J. Math. Anal. Appl., 309(2005), 56-69.

[19] H. SUN AND Y. SHI, Eigenvalues of second-order difference equations with coupled boundary conditions, Linear Algebra Appl., 414 (2006), 361-372.

[20] H. SUN AND J. QI, J -self-adjoint extensions for second-order linear difference equations with complex coefficients, Adv. Difference Equ., 2013 (2013):3.

[21] H. Sun, Q. Kong AND Y. SHI, Essential spectrum of singular discrete linear Hamiltonian systems, Math. Nachr. 289 (2016), 343-359.

[22] M. BOHNER, O. DOS̆LÝ AND W. KRATZ, An oscillation theorem for discrete eigenvalue problems, Rocky Mountain J. Math., 33 (2003), 1233-1260.

[23] M. BOHNER, W. KRATZ AND R. ŠIMON HILSCHER, Oscillation and spectral theory for linear Hamiltonian systems with nonlinear dependence on the spectral parameter, Math. Nachr., 285 (2012), $1343-1356$.

[24] M. Bohner, O. DoŠLÝ AND W. KratZ, Sturmian and spectral theory for discrete symplectic systems, Trans. Amer. Math. Soc., 361 (2009), 3109-3123.

[25] W. KRatz, Discrete Oscillation, J. Difference Equ. Appl., 9 (2003), 135-147.

[26] O. DoŠLÝ AND W. KRATZ, Oscillation theorems for symplectic difference systems, J. Difference Equ. Appl., 13 (2007) 585-605.

[27] O. DOŠLÝ AND W. KRATZ, Oscillation and spectral theory for symplectic difference systems with separated boundary conditions, J. Difference Equ. Appl., 16 (2010), 831-846.

[28] O. DoŠLÝ AND W. KRATZ, A Sturmian separation theorem for symplectic difference systems, J. Math. Anal. Appl., 325 (2007), 333-341.

[29] J. Elyseeva AND R. Simon Hilscher, Discrete oscillation theorems for symplectic eigenvalue problems with general boundary conditions depending nonlinearly on spectral parameter, Linear Algebra Appl., 558 (2018) 108-145.

[30] P. ŠEPITKA AND R. SIMON Hilscher, Singular Sturmian separation theorems for nonoscillatory symplectic difference systems, J. Difference Equ. Appl., 24 (2018), 1894-1934.

[31] R. SimON HILSCHER, Spectral and oscillation theory for general second order Sturm-Liouville difference equations, Adv. Difference Equ., 2012, (2012):82.

[32] J. JI AND B. YANG, Eigenvalue comparisons for second order difference equations with Neumann boundary conditions, Linear Algebra Appl., 425 (2007), 171-183.

[33] J. JI AND B. YANG, Eigenvalue comparisons for second order difference equations with periodic and antiperiodic boundary conditions, J. Appl. Math. Comput., 27 (2008), 307-324.

[34] R. MA, C. GAO AND Y. Lu, Spectrum of discrete second-order Neumann boundary value problems with sign-changing weight, Abstr. Appl. Anal., 2013(2013), Article ID 280508, 10 pages.

[35] R. MA AND C. GAO, Spectrum of discrete second-order difference operator with sign-changing weight and its applications, Discrete Dyn., Nat. Soc., 2014(2014), Article ID 590968, 9 pages.

[36] R. MA, C. GAO, X. HAN AND X. CHEN, Global structure of positive solutions of a discrete problem with sign-changing weight, Discrete Dyn. Nat. Soc., 2011(2011), Article ID 624157, 12 pages.

[37] C. GAO AND R. MA, Eigenvalues of discrete linear second-order periodic and antiperiodic eigenvalue problems with sign-changing weight, Linear Algebra Appl., 467 (2015), 40-56.

[38] C. GAO, R. MA AND F. Zhang, Spectrum of discrete left definite Sturm-Liouville problems with eigenparameter-dependent boundary conditions, Linear Multilinear Algebra, 65(2017), 1905-1923. 